\title{
KEWIRAUSAHAAN DENGAN MENGANGKAT POTENSI UNGGULAN DAERAH DI KECAMATAN LOKSADO, KABUPATEN HULU SUNGAI SELATAN KALIMANTAN SELATAN TAHUN 2018
}

\author{
Nurhikmah $^{1 *}$, Devi Rusvitawati ${ }^{2}$, Alfiannor $^{3}$, Nor Anisa $^{4}$, \\ M. Rio Mursyid Wijaya ${ }^{5}$, Chumaidi ${ }^{6}$ \\ 1,2,3,4,5 STIMI Banjarmasin \\ *Email : nurhikmahdardi09@gmail.com
}

\begin{abstract}
ABSTRAK
Ketersediaan sumberdaya yang melimpah di berbagai daerah di Indonesia memunculkan berbagai potensi produk dan bahkan di beberapa daerah, produk tersebut menjadi unggulan dan menjadi sumber mata pencaharian utama masyarakat setempat . Namun sayangnya, ketersediaan sumber daya yang melimpah tidak menjamin keberhasilan dalam pengembangan produk unggulan daerah. Belum diterapkannya manajemen strategis yang baik dalam proses pengembangan, sistem pemasaran, ijin usaha, kemasan/tampilan produk, promosi, informasi, bahan baku, permodalan dan berbelitnya layanan birokrasi untuk Usaha Kecil dan Menengah (UKM) diindikasi menyebabkan produk unggulan belum dapat dikembangkan secara maksimal. Penerapan manajemen strategis dalam pengembangan produk unggulan keluran menjadi alternatif dari berbagai permasalahan yang terjadi dalam pengebangan produk unggulan desa di Indonesia. Agar masyarakat lebih memahami tentang penerapan manajemen strategis didalam mengembangkan produk unggulan desa maka dilakukanlah penyuluhan kepada para wirausahawan(i) di Kecamatan Loksado dengan tujuan menambah pengetahuan, wawasan, serta pemahaman para wirausahawan(i) sebagai motor penggerak masyarakat didalam peningkatan pemberdayaan masyarakat. Khalayak sasaran dari pengabdian ini yaitu para wirausahawan(i) di Kecamatan Loksado. Biaya pengabdian diperoleh dari STIMI Banjarmasin. Pengabdian telah dilakukan pada tanggal 27 Agustus 2018 yang bertempat di Kecamatan Loksado yang diikuti oleh 22 wirausahawan(i) Dari hasil evaluasi diperoleh manfaat dari kegiatan pengabdian ini yaitu diantaranya meningkatkan Pengetahuan dan pemahaman wirausahawan(i) Kecamatan Loksado dalam mengembangkan produk unggulan desa melalui penerapan manajemen strategis. Kegiatan pengabdian ini berjalan lancar karena dukungan terutama partisipasi dan antusiasme peserta dalam mengikuti kegiatan penyuluhan. Kegiatan penyuluhan ini hendaknya dilakukan pada sasaran yang lebih luas dan materinya dapat dikembangkan pada penerapan Manajemen Strategis di berbagai produk UMKM. Dengan Demikian diharapkan kelak dapat membantu para wirausahawan(i) dalam mengembangkan produk unggulan desa di Kecamatan Loksado sehingga dapat membantu dalam pemberdayaan Masyarakat.
\end{abstract}

Kata kunci : Kewirausahaan, Potensi Unggulan Daerah

\section{ENTREPRENEURSHIP WITH RISING THE POTENTIAL REGIONAL LEADERS IN LOKSADO DISTRICT, HULU SUNGAI SELATAN, KALIMANTAN SELATAN DISTRICT, 2018}

\begin{abstract}
The availability of abundant resources in various regions in Indonesia raises various potential products and even in some areas, these products are superior and become the main source of livelihood for local communities. But unfortunately, the availability of abundant resources does not guarantee success in developing regional superior products. The absence of good strategic management in the development process, marketing systems, business permits, product packaging / display, promotion, information, raw materials, capital and bureaucratic service bureaucracy for Small and Medium Enterprises (SMEs) are indicated to cause superior products not being maximally developed. . The application of strategic management in developing superior products is an alternative to the various problems that occur in the development of superior village products in Indonesia. In order for the
\end{abstract}


BAKTI BANUA : Jurnal Pengabdian Kepada Masyarakat

Volume 1 No. 2 November 2020

e-ISSN : 2722-3736

p-ISSN : 2722-7529

https://ejurnal.stimi-bjm.ac.id/index.php/BBJM/

community to better understand the application of strategic management in developing superior village products, counseling was carried out to entrepreneurs (i) in Loksado District with the aim of increasing knowledge, insight, and understanding of entrepreneurs (i) as a motor driving community in increasing community empowerment. The target audience of this service is entrepreneurs (i) in Loksado District. Service fees were obtained from STIMI Banjarmasin. The service was carried out on 27 August 2018 which took place in Loksado District which was attended by 22 entrepreneurs (i) From the results of the evaluation, the benefits of this service activity were obtained, namely increasing the knowledge and understanding of entrepreneurs (i) Loksado District in developing superior village products through management implementation strategic. This service activity ran smoothly because of the support, especially the participation and enthusiasm of the participants in participating in extension activities. This outreach activity should be carried out on a broader target and the material can be developed in the application of Strategic Management in various UMKM products. With this, it is hoped that one day it can help entrepreneurs $(i)$ in developing superior village products in Loksado District so that they can help in community empowerment.

Keyword : Entrepreneurship, Regional Leading Potential

\section{PENDAHULUAN}

Kewirausahaan mengangkat potensi unggulan daerah saat ini telah menjadi prospek bisnis yang menjanjikan. Keberadaan para pelaku usaha yang tidak ada matinya, seakan menunjukkan bahwa usaha daerah patut dikedepankan dan dikembangkan serta menjadi perhatian bagi semua pihak. Berbagai potensi dan berlimpahnya sumber daya alam yang tersedia menjadikan dukungan tersendiri buat pelaku usaha untuk memperoleh bahan baku sesuai dengan bidang usaha yang ditekuninya. Pengembangan Kewirausahaan mengangkat potensi unggulan daerah yang sedang digalakkan ini selaras dengan Visi 2025, yang diwujudkan melalui 3 (tiga) hal yaitu: (1) Peningkatan nilai tambah dan perluasan rantai nilai proses produksi serta distribusi dari pengelolaan aset dan akses (potensi) SDA, geografis wilayah, dan SDM, melalui penciptaan kegiatan ekonomi yang terintegrasi dan sinergis di dalam maupun antarkawasan pusat-pusat pertumbuhan ekonomi, (2) Mendorong terwujudnya peningkatan efisiensi produksi dan pemasaran serta integrasi pasar domestik dalam rangka penguatan daya saing dan daya tahan perekonomian nasional, (3) Mendorong penguatan sistem inovasi nasional di sisi produksi, proses, maupun pemasaran untuk penguatan daya saing global yang berkelanjutan, menuju innovation driven economy (ekonomi berbasis inovasi).

Atas dasar hal tersebut di atas Sekolah Tinggi Ilmu Manajemen Indonesia (STIMI) Banjarmasin melalui Unit Kegiatan Pusat Penelitian dan Pengabdian pada Masyarakat (P2M) yang merupakan komponen dari Tri Dharma Perguruan Tinggi ingin mengambil peran untuk mengimplementasikan ilmu dan keahliannya di masyarakat melalui kegiatan Sosialisasi \& Pengabdian Masyarakat dengan mengangkat tema Kewirausahaan dengan Mengangkat Potensi Unggulan Daerah dibeberapa Kabupaten/Kota di Kalimantan Selatan.

Bagaimana mendorong/menumbuhkan pemberdayaan masy melalui penguatan sistem inovasi produk lokal Loksado di sisi produksi, proses, maupun pemasaran untuk penguatan daya saing yang berkelanjutan?

Untuk mendorong/menumbuhkan pemberdayaan masy melalui penguatan sistem inovasi produk lokal Loksado di sisi produksi, proses, maupun pemasaran untuk penguatan daya saing yang berkelanjutan.

\section{BENTUK KEGIATAN}


BAKTI BANUA : Jurnal Pengabdian Kepada Masyarakat

Volume 1 No. 2 November 2020

e-ISSN : 2722-3736

p-ISSN : 2722-7529

https://ejurnal.stimi-bjm.ac.id/index.php/BBJM/

Sosialisasi dan Pengabdian pada Masyarakat Kewirausahaan Mengangkat Potensi Unggulan Daerah bagi masyarakat desa/daerah yang memiliki usaha berupa produk pangan dan kerajinan tangan atau industry rumahan yang perlu mendapatkan pembinaan bagi peningkatan hasil dari produk unggulan desa/daerahnya, khusus untuk Kecamatan Loksado yyang tersebar di 11 desa.

Metode yang diterapkan dalam kegiatan pengabdian ini adalah :

1. Menumbuhkan Jiwa Kewirausahaan Masy melalui Kesadaran atas Potensi Unggulan Daerah.

2. Mengembangkan Teknis Pengemasan dan Pemasaran Produk yang dapat diproduksi oleh masy lokal dengan murah, mudah dan diminati konsumen.

3. Pada kesempatan ini pendekatan nondirektif (partisipatif) dengan asumsi bahwa masy sudah cukup mengetahui produk yg dikembangkan dan dibutuhkan konsumen. Dgn demikian, melalui pendekatan ini pelaksanana pengabdi masy bertugas menggali dan mengembangkan potensi masy. Dan pemeran utamanya adalah masy itu sendiri, melalui tahapan-tahapan.

\section{MATERI DAN NARASUMBER}

\section{NARASUMBER :}

Dr. Titien Agustina, M.Si. $\quad$ : Dosen STIMI Banjarmasin, Judul Materi $\quad$ : Teknis Pengemasan dan Pemasaran Produk.

HJ. Sampurnawati, S.E. $\quad$ : Praktisi dan Trainer Kewirausahaan Kalimantan Selatan, Judul Materi : Menumbuhkan Jiwa Kewirausahaan Masyarakat Melalui Kesadaran Atas Potensi Unggulan Daerah.

\section{MODERATOR :}

Nurhikmah, S.H., M.H., M.M. : Dosen STIMI Banjarmasin

Masyarakat yang memiliki usaha industrI rumahan baik berupa pangan dan kerajinan yang berada di 11 desa di Kecamatan Loksado, Kab. HSS, masing-masing desa mengirimkan 2 orang (Dokumen terlampir).

\section{HASIL DAN PEMBAHASAN}

Hasil yang dicapai dalam pengabdian masy ini ialah bahwa dengan adanya kegiatan ini dapat kiranya membantu produk lokal loksado agar bisa dikenal dan memasuki pasar, dengan cara penyempurnaan dalam kemasan agar lebih menarik sesuai standar serta dipasarkan tidak hanya secara offline tetapi juga online karena kita telah berada di era industri 4.0.

Adapun tahapan-tahapannya :

1. Melakukan pendekatan terhadap masy yang berwirausaha di Kec. Loksado yg memproduksi unggulan lokal spt kerupuk talas loksado dan sirup kayu manis, agar mengembangkan produk khas daerah ini. 
BAKTI BANUA : Jurnal Pengabdian Kepada Masyarakat

Volume 1 No. 2 November 2020

e-ISSN : 2722-3736

p-ISSN : 2722-7529

https://ejurnal.stimi-bjm.ac.id/index.php/BBJM/

2. Melakukan kerjasama dengan OPD/SKPD terkait untuk mau membantu program yg dilaksanakan.

3. Melakukan kegiatan pengabdian melalui kegiatan pelatihan yg melibatkan praktisi, terutama dlm pengembangan produk unggulan daerah dan proses pembautannya.

4. Melakukan RTL berupa monev secara internal dan ekternal .

5. Kelompok masy penerima pengabdian yg menjadi mitra diberi kesempatan unt konsultasi secara langsung dan tidak langsung jika mengalami kendala dalam usahanya.

\section{KESIMPULAN}

Wirausaha(i) di kecamatan Loksado sangat potensial untuk diberdayakan dalam menggali sumberdaya alam setempat seperti pembuatan sirup kayumanis dan keripik talas loksado. Kegiatan PKM untuk menumbuhkan pemberdayaan masy melalui penguatan sistem inovasi produk lokal Loksado di sisi produksi, proses, maupun pemasaran untuk penguatan daya saing yang berkelanjutan. Keterampilan dan pengetahuan peserta dapat menjadi tambahan modal untuk meningkatkan pendapatan dan kesejahteraan masyarakat di Kecamatan Loksado

\section{RENCANA TINDAK LANJUT}

Bekerjasama dengan OPD Pemda (seperti Dinas Koperasi UKM, Dinas Perindustrian dan Perdagangan, serta Dinas Pariwisata) setempat dalam hal pembinaan dan pengaasan produk serta akses permodalan dan pemasaran.Menjalin kerjasama dengan swasta dalam rangka kegiatan CSRnya dan lembaga/organisasi profesi terkait. Pembentukan unit usaha bersama melalui Koperasi

\section{DAFTAR PUSTAKA}

Agustina, Titien; Candrarin, G.; Manan, A. (2017). MSMEs Challenges in Phenomena of Disruption Era. Journal of Economics and Sustainable Development, 8(21), 116-121.

Agustina, T. (2019). Improving Business Performance Through Competitive Advantage: A Study On SMES In Banjarmasin, Indonesia. Eurasia: Economic \& Business, 6(26), 39-59.

Dipta, I Wayan. 2009. Mengangkat Peran Perempuan Pengusaha Dalam Mengatasi Pengangguran. Kalarta: Kementerian Negara, Koperasi dan UKM.

Kusumawardani, Indah. 2013. Metode-Metode Penyuluhan. http://indaharitonangfakultaspertanianunpad.blogspot.com/2013/06/metode-metode-penyuluhan.html. Diakses, 16 April 2020.

Panggabean, Hasugian, M. dan. (2019). Peran Perempuan dalam Mengembangkan Usaha Mikro Kecil dan Menengah dalam rangka menuju Masyarakat Ekonomi ASEAN di Kota Tangerang Selatan. 2(2), 111-135.

Priminingtyas, D. N. (2010). Peran Perempuan Dalam Pengembangan Sektor Usaha Mikro Kecil Menengah (UMKM). 1-7. 
BAKTI BANUA : Jurnal Pengabdian Kepada Masyarakat

Volume 1 No. 2 November 2020

e-ISSN : 2722-3736

p-ISSN : 2722-7529

https://ejurnal.stimi-bjm.ac.id/index.php/BBJM/

Suryana. (2013). Kewirausahaan. Jakarta: Kencana.

Tambunan, T. (2012). Usaha Mikro Kecil dan Menengah di Indonesia: Isu-isu Penting. Jakarta: LP3ES.

Widayat, et. al. (2018). Pengembangan Produktivitas dan Kewirausahaan Bagi Usaha Kecil di Kelurahan Sukaramai Kecamatan Pekanbaru Kota. Jurnal Bakti Saintek: Jurnal Pengabdian Masyarakat Bidang Sains Dan Teknologi, 2(2), 51. https://doi.org/10.14421/jbs.1217 